\title{
Calcification of the ligamentum flavum in the thoracolumbar spine: an unusual cause of compressive myelopathy
}

\author{
João Augusto dos Santos Martines ${ }^{a}$, Brenda Margatho Ramos Martines ${ }^{a}$, \\ José de Arimatéia Batista Araújo Filho ${ }^{b}$, Lorena Elaine Amorim Pinto ${ }^{b}$, Cláudio Campi de Castro ${ }^{a, c}$
}

Martines JAS, Martines BMR, Araujo Filho JAB, Pinto LEA, Castro CC. Calcification of the ligamentum flavum in the thoracolumbar spine: an unusual cause of compressive myelopathy. Autopsy Case Rep [Internet]. 2012;2(2):25-29. http://dx.doi.org/10.4322/acr.2012.013

\section{ABSTRACT}

The focal calcification or ossification of the ligamentum flavum is a rare cause of thoracic myelopathy and most often occurs among individuals of Japanese descent. It is rare in other ethnic groups and in individuals below the age of 50 . It is most often described at the lower thoracic level, being uncommon in the lumbar region and rare in the cervical region. Here, we present the case of a 44-year-old White female patient who sought medical attention with an eightmonth history of paraesthesia of the lower limbs and progressive difficulty in walking. The clinical profile, together with computed tomography and nuclear magnetic resonance imaging of the spine, led to a diagnosis of compressive thoracic myelopathy due to ossification of the ligamentum flavum in the thoracic and lumbar spine. The patient underwent laminectomy and dissection of some of the affected ligamentum flavum, without any intraoperative complications. After three months of clinical follow-up, the patient had progressed favorably, having no sensory complaints and again becoming ambulatory.

Keywords: Ossification of the posterior longitudinal ligament; Spine; Ligamentum flavum; Spinal cord compression.

\section{CASE REPORT}

A previously healthy 44-year-old White female patient sought medical attention at our hospital. The patient presented with a 2-month history of ascending paresthesia of the left leg, with progressive worsening and right leg involvement, accompanied by reduced (right and left) leg muscle strength. She reported lower back discomfort and abdominal paresthesia. Clinical findings were normal. Neurological examination revealed paraparesis (grade 1/2 muscle power in the right leg and grade $2 / 3$ muscle power in the left), as well as pyramidal signs and brisk reflexes in the legs, together with a sensory level of T8 on both sides and pain on movement of the thoracic spine. A computed tomography (CT) scan of the thoracolumbar spine revealed the following (Figures 1-4): in the thoracic region-ligamentum flavum (LF) hypertrophy and calcification, which caused narrowing of the spinal canal and lateral recess, the narrowing being greatest at T6 and at T10-T11; and, in the lumbar

\footnotetext{
a Diagnostic Imaging Service - Hospital Universitário - Universidade de São Paulo, São Paulo/SP - Brazil.

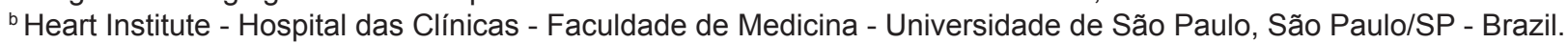

c Department of Radiology - Faculdade de Medicina - Universidade de São Paulo, São Paulo/SP - Brazil.
} 


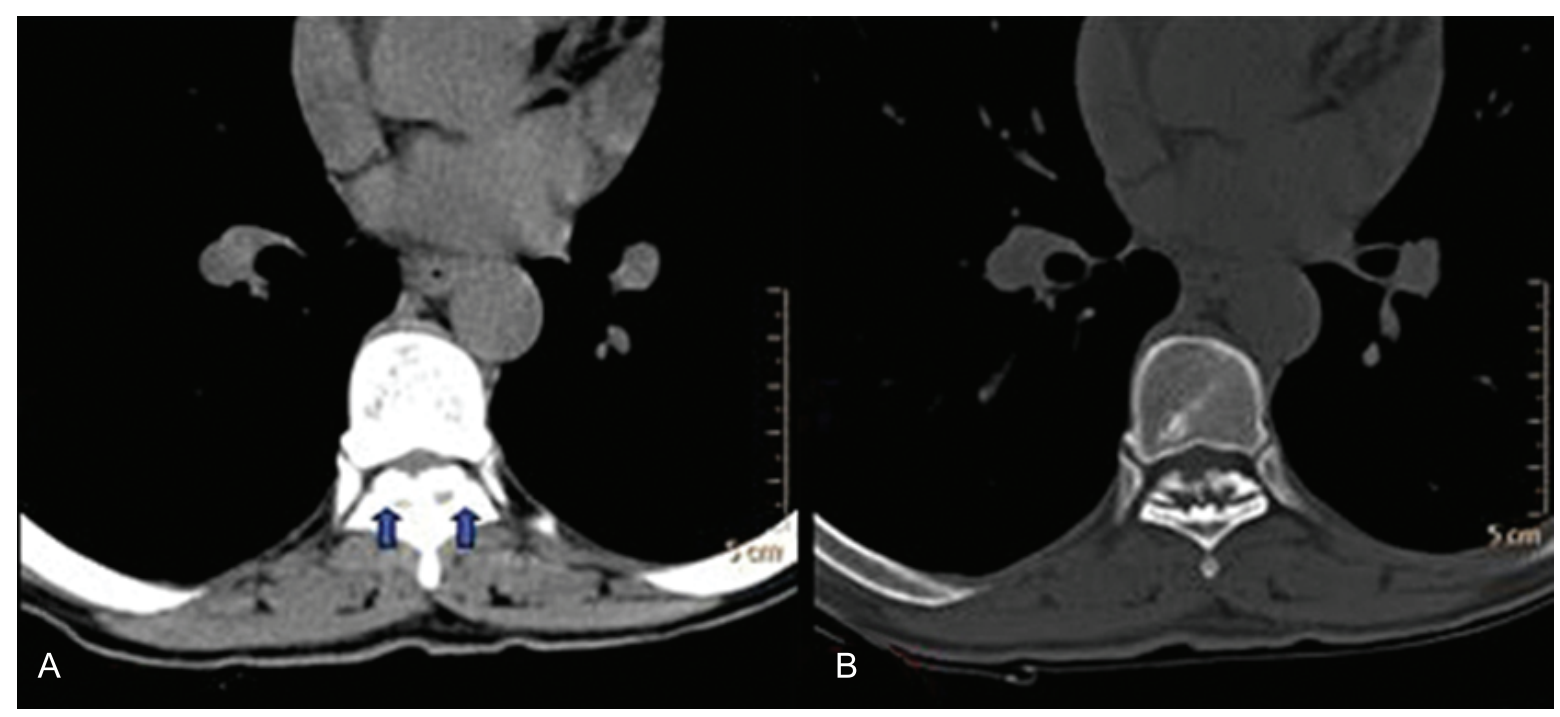

Figure 1 - Axial soft tissue window and bone window computed tomography scans (A and $\mathbf{B}$, respectively) of the thoracic spine showing hypertrophied and calcified ligamenta flava (arrows) causing spinal canal narrowing.

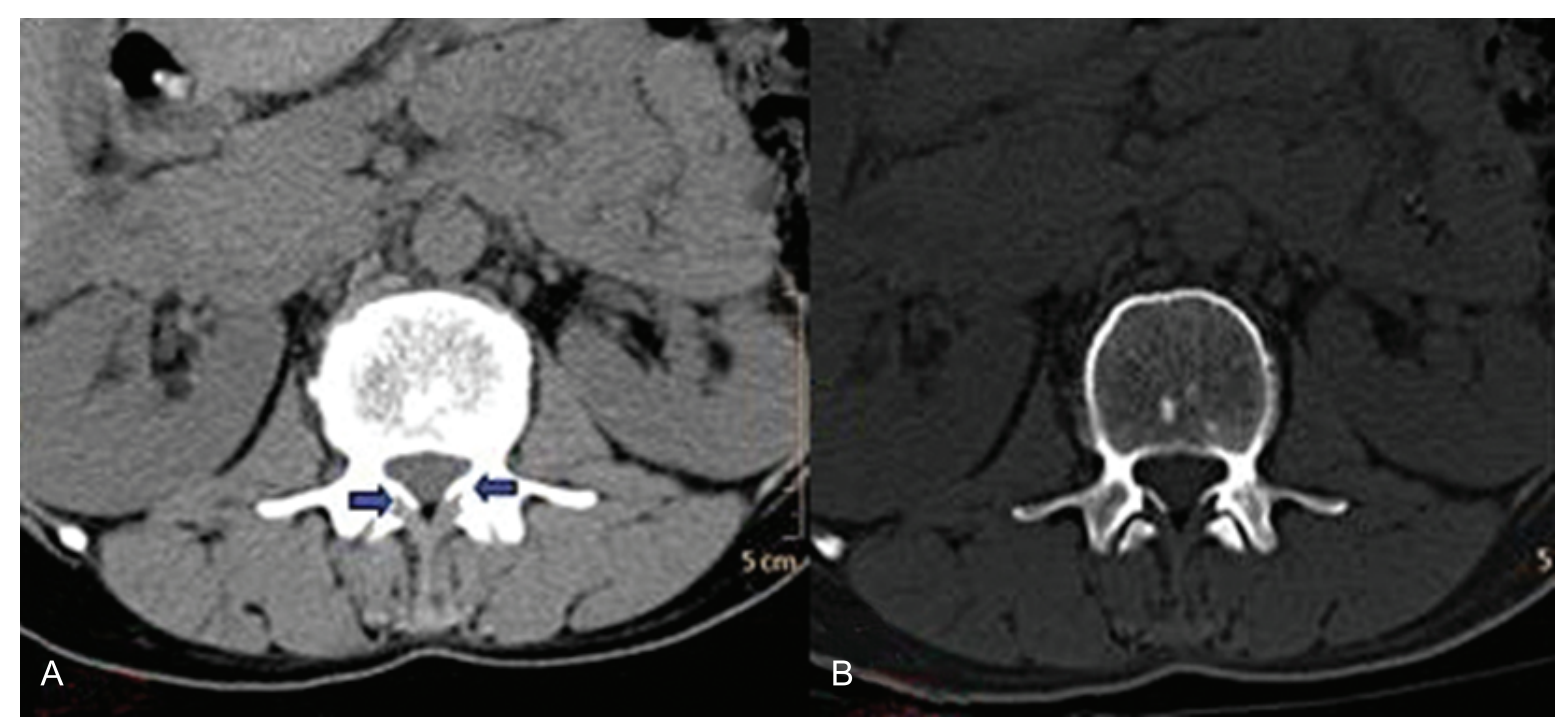

Figure 2 - Axial soft tissue window and bone window computed tomography scans (A and B, respectively) of the lumbar spine showing calcified ligamenta flava (arrows) causing no spinal canal narrowing.

region-LF hypertrophy and calcification at L1-L2, with a herniated disc at L4-L5 and diffuse marginal osteophytes.

Magnetic resonance imaging (MRI) showed hyperintense signals on T2-weighted images at T6-T7 and T10-T11; those vertebrae were slightly thinner, suggesting concomitant myelomalacia (Figure 5). Laboratory test results were normal, metabolic disorders being therefore ruled out.

The patient underwent laminectomy and dissection of some of the affected LF, without any intraoperative complications. After three months of clinical follow-up, the patient had progressed favorably, having no sensory complaints and again becoming ambulatory.

\section{DISCUSSION}

Although uncommon, ossification or calcification of the LF as a cause of thoracolumbar myelopathy has been extensively described in Eastern populations, particularly in individuals of Japanese descent. ${ }^{1-7}$ Despite the significant number of Japanese immigrants in Brazil, there is an obvious lack of studies on the topic in the country.

The LF are elastic connective tissue ligaments that lie on a crest bone located on the lower border of the vertebral lamina, extending to the upper border of the lamina of the underlying vertebral body and contributing to forming the posterior limit of the intervertebral foramen (Figure 6). The elasticity of the LF decreases with age; in elderly individuals, 


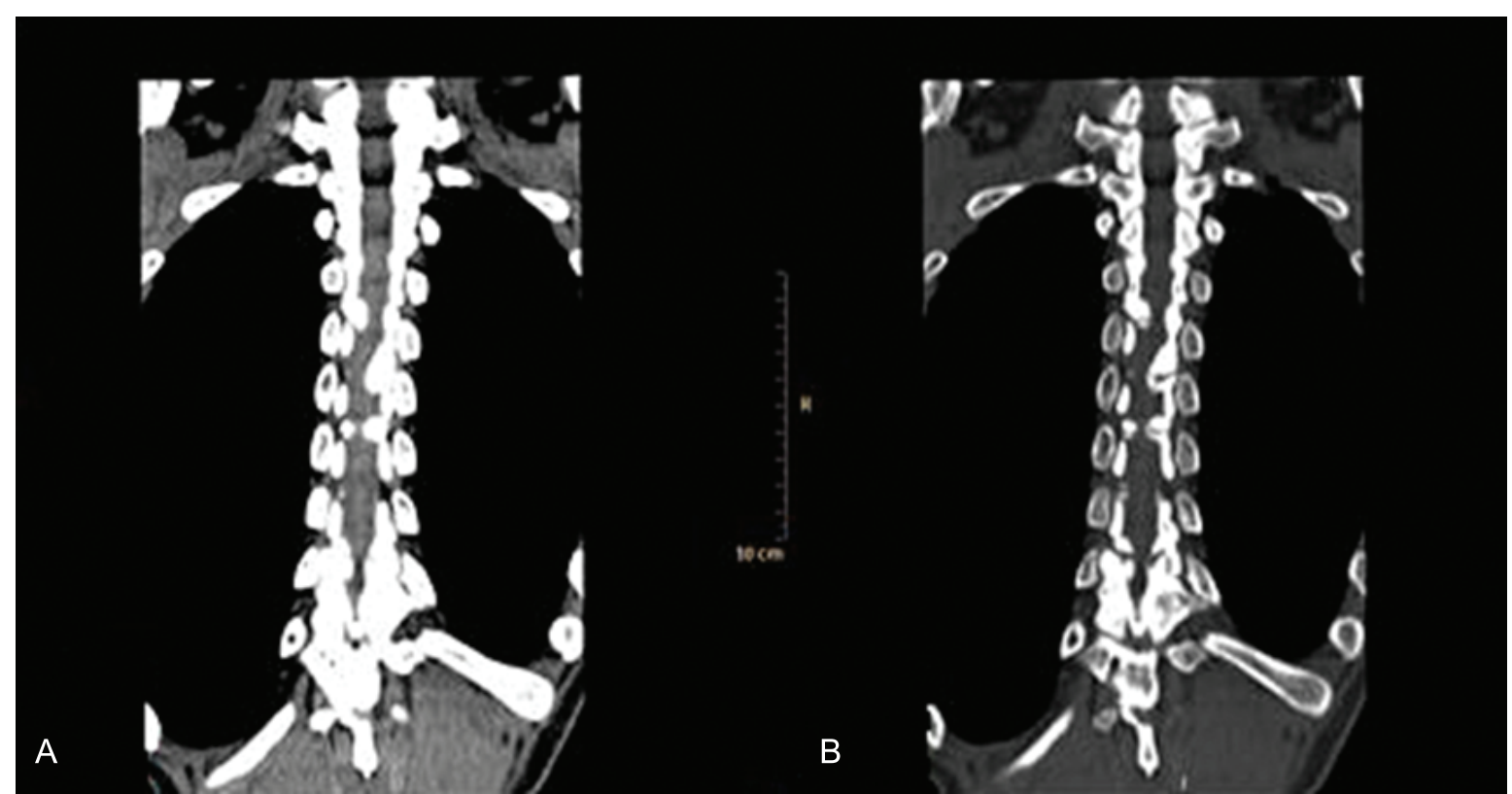

Figure 3 - Coronal reconstruction of soft tissue window and bone window computed tomography scans (A and $\mathbf{B}$, respectively) of the thoracic spine showing hypertrophied and calcified ligamenta flava causing spinal canal narrowing, which is most evident at T6, T10, and T11.

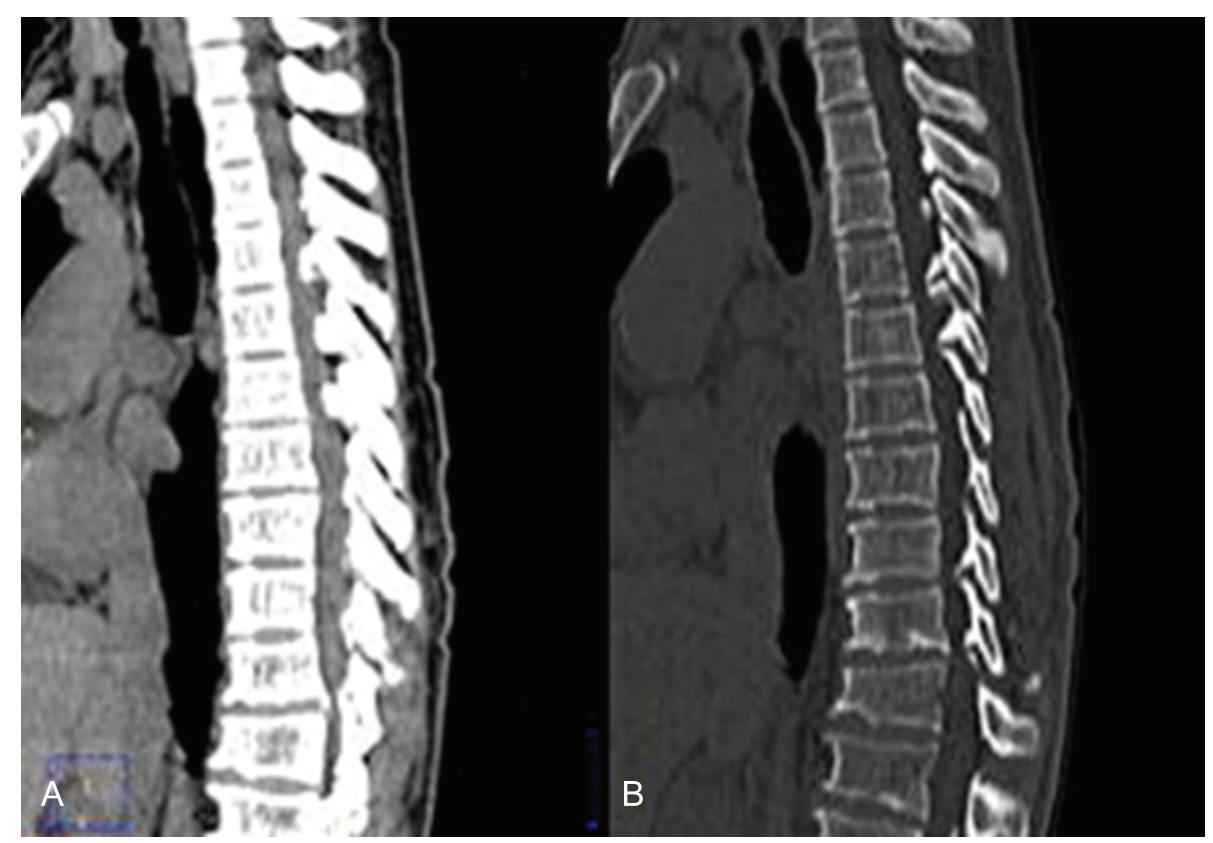

Figure 4 - Sagittal reconstruction of soft tissue window and bone window computed tomography scans (A and $\mathbf{B}$, respectively) of the thoracic spine showing hypertrophied and calcified ligamenta flava causing spinal canal narrowing, which is most evident at T6, T10, and T11.

sudden and forced extension movements can cause cervical cord compression. ${ }^{8}$

Histologically, there is a variety of pathological conditions affecting the LF, including hypertrophy, calcification, and ossification. In cases of hypertrophy, the normal fibrous structure of the LF is replaced by hypertrophic fibrous tissue containing numerous fibrocartilaginous cells with abundant matrix. $^{9}$ Such calcification consists of thickening of the deep layers of the LF, whereas the corresponding ossification affects only the most superficial layers. ${ }^{10}$

Ossification or calcification of the LF is an idiopathic endochondral calcification that affects approximately $20 \%$ of individuals who are of Eastern origin and who are older than 60 years of age, ${ }^{11}$ being rare in those who are not of Eastern origin and in those who are younger than 50 years 


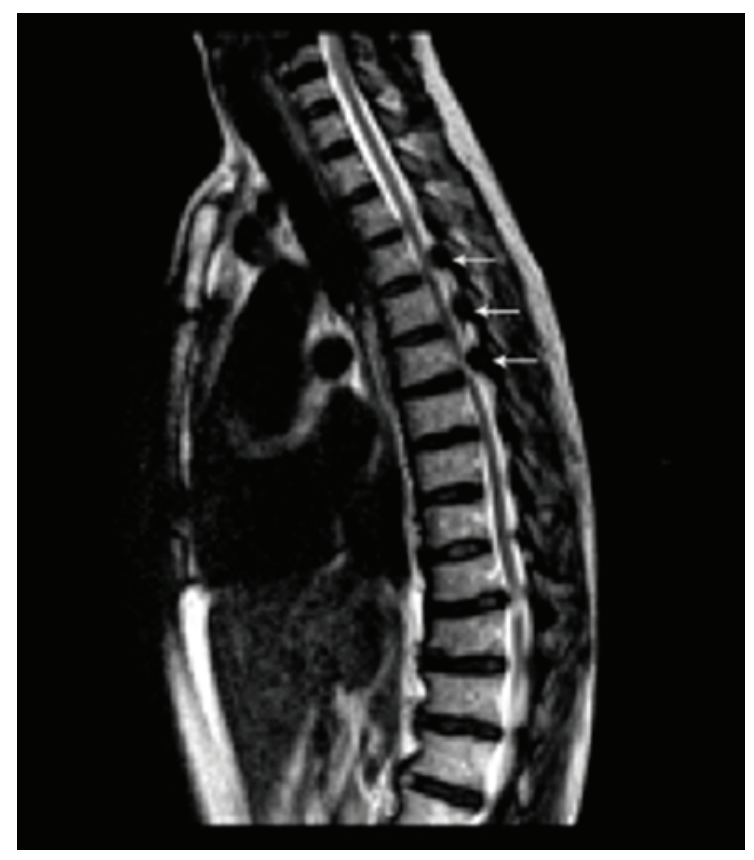

Figure 5 - Magnetic resonance imaging of the thoracic spine: T2-weighted sequence showing hyperintense areas in the spinal cord at T6-T7 and T10-T11, suggesting compressive myelopathy.

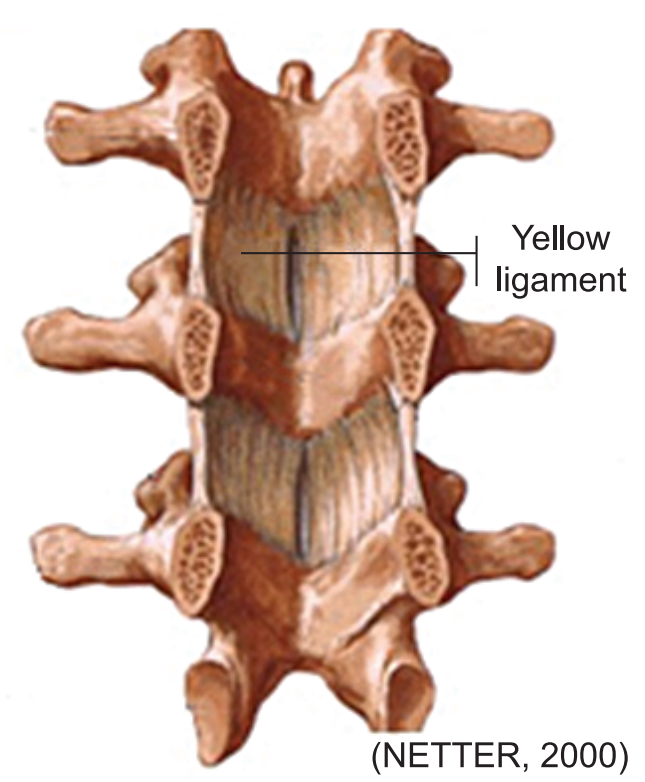

Figure 6 - Topographic anatomy of the ligamentum flavum.

Source: Netter, FH. Atlas de anatomia humana. 2a ed. Porto Alegre: Artmed; 2000.

of age, as was the case here. In fact, the etiology of this calcification/ossification remains unclear. Although the role of initial trauma has yet to be demonstrated, it is known that such trauma can worsen the neurological symptoms. ${ }^{12}$ Ossification or calcification of the LF is most common at the lower thoracic level, being uncommon in the lumbar region (as was the case here) and rare in the cervical region. ${ }^{11}$ The region most often affected in women is the cervical region, whereas it is the thoracic and lumbar regions in men. ${ }^{11}$

The typical clinical presentation is chronic myelopathy with cervicothoracic cord compression, which can be accompanied by radiculopathy and sphincter dysfunction. Ossification or calcification of the LF can be associated with Paget's disease, rickets, chondrocalcinosis, ankylosing spondylitis, hypoparathyroidism, skeletal hyperostosis, obesity, diabetes, hyperinsulinemia, and disorders of calcium metabolism. ${ }^{11}$ None of the abovementioned conditions were confirmed in the case reported here.

Although X-ray and myelography findings can suggest the diagnosis, the two methods generally have limited value. A CT scan can reveal a calcified/ ossified extradural mass located under the vertebral lamina and protruding into the intervertebral foramen, with a loss of extradural fat. ${ }^{11}$ In determining the degree of spinal cord compression and the characteristics of ossification, MRI is extremely useful, the LF appearing hypointense on T1- and T2-weighted images. The typical indentation is best seen on T2-weighted images. ${ }^{11}$ The use of CT and MRI in combination provides information that is more accurate and useful for treatment planning than does the use of either alone. ${ }^{4,9}$

The treatment of ossification or calcification of the LF generally consists of posterior surgical decompression by laminectomy or laminoplasty with joint preservation, which increases the stability of the spinal column. ${ }^{11}$ The prognosis is variable but typically favorable. However, the course of the disease is sometimes severe because of the size and extent of the stenosis. Nevertheless, a physical therapy rehabilitation program should be started gradually, as early as in the immediate postoperative period. ${ }^{11}$

In conclusion, albeit rare (except in individuals of Japanese descent), ossification or calcification of the LF can lead to spinal cord compression due to spinal canal stenosis. The diagnosis is preferably made by MRI and CT in combination. The prognosis is variable, sometimes being poor because of the size and extent of stenosis. A better understanding of the disease could increase the number of cases diagnosed in patients who are not of Japanese descent. 


\section{REFERENCES}

1. Kubota M, Baba I, Sumita T. Myelopathy due to ossification of the ligamentum flavum of the cervical spine: a report of two cases. Spine. 1981;6:553-9. PMid:6801782. http:// dx.doi.org/10.1097/00007632-198111000-00005

2. Takayama S, Kuribayashi K, Miyamoto Y, Nakasu Y, Handa J. Ossification and calcification of the cervical ligamentum flavum. No To Shinkei. 1993;9:859-63.

3. Yoshida H, Murao S, Nakajima T, Tsutsumi T. Paraplegia caused by ossification of the ligamentum flavum. Nippon Rinsho. 1976;10:3085-90 .

4. Hanakita J, Suwa H, Ohta F, Nishi S, Sakaida H, lihara K. Neuroradiological examination of thoracic radiculomyelopathy due to ossification of ligamentum flavum. Neuroradiology. 1990;32:38-42. PMid:2110325. http:// dx.doi.org/10.1007/BF00593939

5. Hukuda S, Mochizuki T, Ogata M, Schichikawa K. The pattern of spinal and extraspinal hyperostosis in patients with ossification of the posterior longitudinal ligament and the ligamentum flavum causing myelopathy. Skeletal Radiol. 1983;10:79-85. PMid:6612370. http://dx.doi. org/10.1007/BF00360789

6. Myakasa K, Kaneda K, Sato S, et al. Myelopathy due to ossification or calcification of the ligamentum flavum:

\section{Conflict of interest: None}

Submitted on: 10 ${ }^{\text {h }}$ February 2012

Accept on: 26 $6^{\text {th }}$ February 2012

Correspondence: Instituto do Coração - Incor HCFMUSP Av. Dr. Enéas Carvalho de Aguiar, 44 - São Paulo/SP - Brazil 05403-900 - Phone: 55 (11) 2661.5000

E-mail: ariaraujocg@hotmail.com radiologic and histologic evaluations. AJNR. 1983;4:62932. PMid:6410817.

7. Yamashita $\mathrm{Y}$, Takahashi M, Matsuno $\mathrm{Y}$, et al. Spinal cord compression due to ossification of ligaments: MR imaging. Radiology. 1990;175:843-8. PMid:2111569.

8. Johnson RM, Murphy MJ, Sothwick WO. Surgical approaches to the spine. In: Rothman $\mathrm{RH}$, Simeone FA, editors. The Spine. 3rd ed. Philadelphia: WB Saunders; 1992. p. 1623-8.

9. Okada K, Oka S, Tohge K, Ono K, Tunenobu K, Hosoya $\mathrm{T}$. Thoracic myelopathy caused by ossification of the ligamentum flavum. Spine. 1991;16:280-7. PMid:1902988. http://dx.doi.org/10.1097/00007632-199103000-00005

10. Akino $M$, Abe $H$, Iwasaki $Y$, et al. A case of cervical myelopathy due to calcified mass in the cervical yellow ligament. Neurol Surg (Tokyo). 1983;11:173-8.

11. Gondim, J, Ramos Junior, F. Compressão medular torácica em dois níveis por calcificação de ligamento amarelo: relato de caso. Arq neuropsiquiatr. 1998; 56:312-6.

12. Vitale C. Ossification du ligament vertebrál commun postérieur de la region cervicale. In: De Sèze S, Ryckewaert A, Kahn MF, Guérin CL. L'actualité rhumatologique. Paris: Expansion Scientifique Française; 1985. p. 144-8. 
